\title{
CMAJ
}
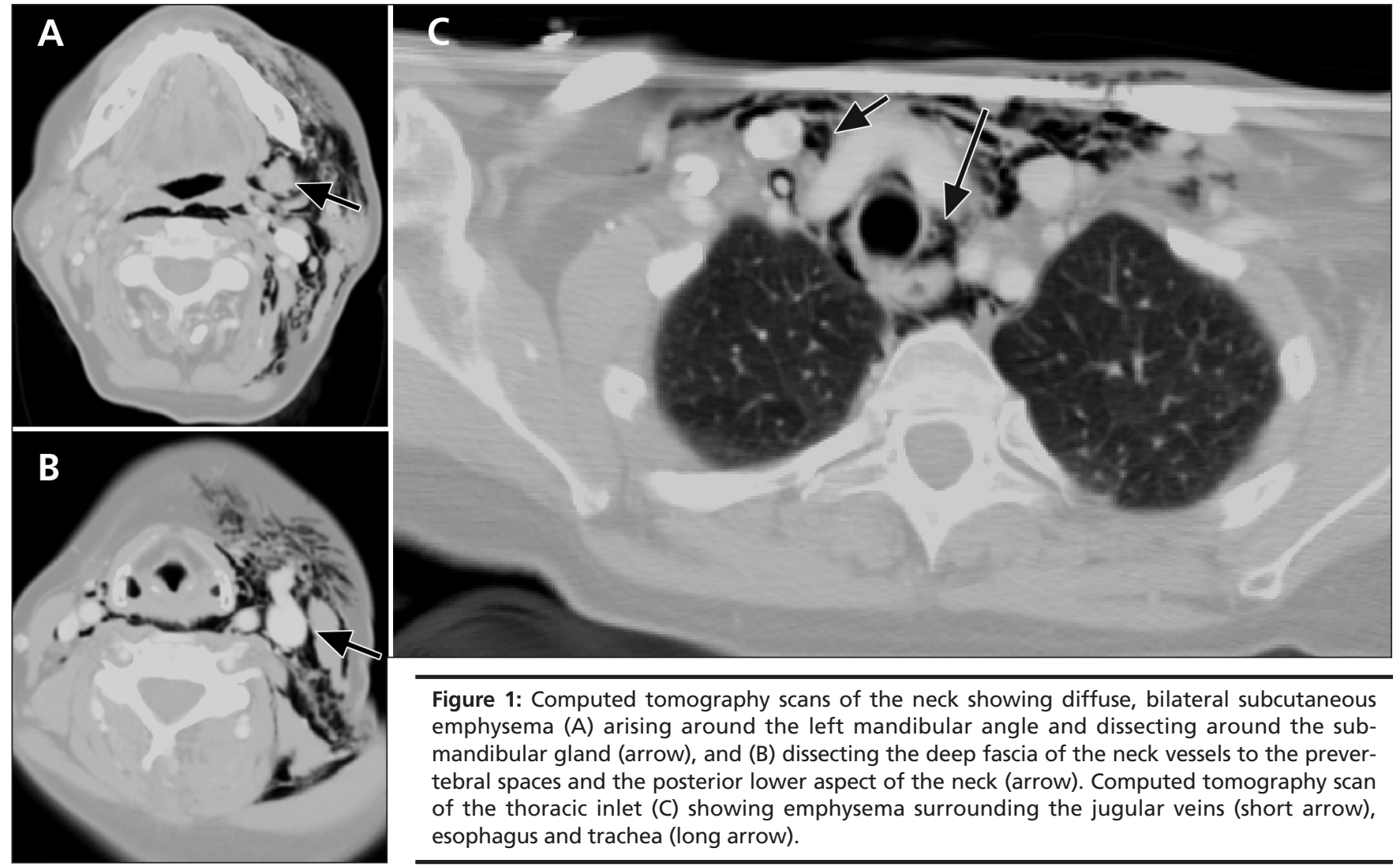

Figure 1: Computed tomography scans of the neck showing diffuse, bilateral subcutaneous emphysema (A) arising around the left mandibular angle and dissecting around the submandibular gland (arrow), and (B) dissecting the deep fascia of the neck vessels to the prevertebral spaces and the posterior lower aspect of the neck (arrow). Computed tomography scan of the thoracic inlet (C) showing emphysema surrounding the jugular veins (short arrow), esophagus and trachea (long arrow).

\section{Facial swelling after a dental procedure}

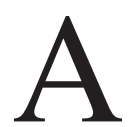

59-year-old woman experienced acute facial swelling about 1 hour after dental repair of a left lower molar cap. The repair had been performed under local anesthetic using a high-pressure drill in the periodontal space. A computed tomography scan showed subcutaneous emphysema (Figure 1). The patient was referred to the otolaryngology service to exclude airway pathology. She was given prophylactic antibiotics and made a full, uneventful recovery.

Subcutaneous emphysema is usually associated with surgery, trauma or infection. Rarely, it can occur after dental treatment. High-speed drills used during dental restoration, extraction and endodontic procedures are driven by a pressurized mixture of air and water. The mixture cools the drill-tooth interface to prevent the enamel and dentin from burning. When applied to the loose connective tissues of the gingiva to expose the tooth below the gum line (particularly at the roots of the first, second and third molars), the pressurized air-water mixture has the potential to dissect the fascia and spread throughout the soft tissues of the face, neck and chest. The onset of symptoms occurs within an hour after the procedure. Most cases begin to improve after 2-3 days of treatment.

Clinical images are chosen because they are particularly intriguing, classic or dramatic.

Submissions of clear, appropriately labelled high-resolution images must be accompanied by a figure caption and the patient's written consent for publication. A brief explanation (300 words maximum) of the educational significance of the images with minimal references is required.
Mariam Ghali Eskander MD BSc

Diagnostic Radiology

London Health Sciences Centre

London, Ont.

Acknowledgement: Special thanks to Dr. David Pelz for reviewing this case report. 